\title{
CLIMATE RISK ASSESSMENT FOR WHEAT PRODUCERS IN BULGARIA
}

\author{
T. Georgieva* \\ University of Economics - Varna, Bulgaria
}

\begin{abstract}
The aim of this paper is to present a methodology for assessing the level of climatic risk in agriculture and to assess the risk of climate variability faced by wheat producers in Bulgaria. The analysis is based on secondary data on the average wheat yield during the period 1998 - 2018. Using a breakpoint linear regression model we estimated the predictable component in the time series of the average crop yield. Climate risk was assessed using a detrended coefficient of variation. We conclude that about $10 \%$ of the average yield variation from its typical value can be explained by the impact of random factors, among which climate variability over the period.
\end{abstract}

Key words: climate variability, yield predictable component, detrended coefficient, variation

\section{INTRODUCTION}

Among the distinctive features of agricultural production is the high level of dependence of natural and climatic factors. Climate risk, along with the risk of adverse and unexpected price movements, is typically high in this sector. The stability of yield is, on the one hand, an important farmers' objective and, on the other hand, a criterion for farmers' crop choice decisions as well as for policy decisions such as subsidies to crop insurance (1). Wheat is the most mass-produced agricultural crop in Bulgaria in recent years, with about 12 million decares $(1$ decare $=0.1$ hectares $)$ of planted areas and over 11.5 decares harvested areas annually (2).

The aim of this paper is to present a methodology for assessing the level of climatic risk in agriculture and to assess the risk of climate variability faced by wheat producers in Bulgaria.

Regardless of the nuances in the definitions used, the term "risk" refers to the probability of deviation of a future event from its expected value $(3,4)$. The term "climate" is to be understood as a set of meteorological elements that characterize the average state of the

\footnotetext{
*Correspondence to: Tanya Georgieva, University of Economics - Varna, Bulgaria, Tanya Georgieva, 9002 Varna 77 Knyaz Boris I Blvd., +358882164604,t.georgieva@ue-varna.bg
}

atmosphere of a given geographical location. Gommes and Fresco (4) analyze different definitions of climate deviations and conclude that the term reflects at least two phenomena. The term "climate change" is often used in the sense of a "significant" change (i.e. a change that has important economic, environmental and / or social effects) of the average values of a meteorological element over a period of time, usually longer than a decade. Different meaning is incorporated in the term climate variability, namely climate deviations over a certain (relatively short) time period (such as month, season, year) of the long-term average. Since short-term fluctuations in the climate result in short-term fluctuations in average yield, it is understood in the literature (4-6) that the risk associated with variations in average yield from its expected value due to climate variability can be estimated by studying the components of the time series of historical yields behavior.

Changes in crop yields are due to the impact of a variety of factors (technological innovation, changes in government policies, climate changes, climate variability, etc.). The impact of only some of these factors on average yields is unpredictable, and therefore - a source of risk. On this basis, a large proportion of agricultural climate risk researchers (4-6) assume that if they are able to evaluate and divide the components of the average yield time series in predictable and unpredictable 
(residuals), the unpredictable / random effects on deviations of the average yield can be used for probabilistic risk assessment.

The estimated and modeled trend is the result of temporal changes in the average value of the target variable and provides information on the overall direction and rate of foreseeable change in crop yield as a result of the long-term impact of factors that affect productivity (in the terms of quantity per unit of harvested area). Such factors can be technological innovations (innovation in mechanization, chemistry, crop selection, irrigation, etc.), management innovation, the acquisition of specific knowledge by farmers (know-how), climate change, national and supranational policies or other long-term effects. Researchers have explored various procedures $(5,6)$, such as linear, loglinear, quadratic, polynomial, autoregressive integrated moving average and piecewise regression trend models in order to detrend the crop yield over time.

Some changes in government policies aimed at increasing agricultural productivity (for example, subsidizing production inputs) can interrupt a trend in average yields and trigger a new one. In this case, the trend of the average yield is not a single linear (or non-linear) function of time, but changes to some breakpoint. For example, the change in the chemical composition of products used for plant protection or fertilization due to environmental regulation can cause a trend break (or critical threshold) in long-term yield dynamics (6). Such effects may also have the effect of subsidies aimed at increasing the technical level of production, promoting technology transfer, stimulating farmers' associations, etc.
Residual values in the time series are deviations of the average yield from its expected value over the years. Probability distribution of the residuals (detrended yield) can be explained by the influence of external environmental factors. Assuming that factors such as pests and diseases influence the average yield relatively constantly and controlled, the residual values are the result of climate variability as the main "random" factor (4), i.e. residual values are the result of climate deviations from the long-term average, causing an increase or decrease in average yields (e.g. drought, floods, hail, occurring in individual years are considered responsible for negative residuals, positive residuals indicate more favorable than average natural and climatic conditions).

\section{METHODS}

We use data on average wheat yield for the period 1998-2018 published in the FAO statistical database (7). The average yield unit of measure was recalculated from $\mathrm{hg} / \mathrm{ha}$ in $\mathrm{kg}$ / decare harvested area. Climate risk assessment consists of three steps. The first step involves trend estimation and detection of trend changes. The second step is to remove (eliminate) the trend from historical data on average yields. The third step involves calculating residual variance.

The first step involves fitting of a smooth curve through the yield statistics. We apply the method of least squares to find the line / curve of best fit that best approximates the trend on a scatter plot. This helps us to visualize the relationship between time and average yield, assuming no structural shocks in the average yield trend. The comparison criteria for different trend types are shown in Table 1.

Table 1. Trend type, trend equation and R-squared value

\begin{tabular}{|l|l|l|}
\hline Trend/ Regression type & Trend equation & $R^{2}$ \\
\hline Linear & $\mathrm{Y}=11,926 \mathrm{X}+231,24$ & 0,724 \\
\hline Exponential & $\mathrm{Y}=247,14 \mathrm{e}^{0,0323 \mathrm{x}}$ & 0,678 \\
\hline Logarithmic & $\mathrm{Y}=76,056 \ln (\mathrm{x})+198,07$ & 0,511 \\
\hline Polynomial & $\mathrm{Y}=0,6665 \mathrm{x}^{2}-2,738 \mathrm{x}+238,45$ & 0,721 \\
\hline Power & $\mathrm{Y}=224,63 \mathrm{x}^{0,2085}$ & 0,491 \\
\hline
\end{tabular}

Based on the data in Table № 1, we can conclude that the linear trendline best approximates this set of data points. A recent study (8) on the impact of single area payment scheme have shown an increase in average wheat yields since 2007, explained by a better resource supply and technological improvements . The financial resource under the Rural Development Program also contributes to the modernization and technological renovation of farms. There is a steady trend of investment growth in fixed assets for agricultural production $(9,10)$. Stimulating the transfer of knowledge and 
innovation in the field of agriculture is one of the priorities of the European Union for rural development in the programming period 20142020. After 2013 each of the measures, submeasures and the combination of measures under the Rural Development Program are expected to be assessed (11) in terms of their potential to contribute to innovation, including discovering and developing new ideas, enhancing the ability of individuals to transfer knowledge and using these new ideas. On the basis of the existing evidence, we assume that there are trend breaks in the long-term dynamics of wheat yield. In order to avoid the problem with so called spurious correlation with time $(12,13)$ we need to test whether the time series variable is non-stationary and possesses a unit root. Table № 2 reports the results of the Dickey-Fuller min-t breakpoint unit root test for the wheat yield.

Table 2. Dickey-Fuller min-t breakpoint unit root test results

\begin{tabular}{|c|c|c|c|}
\hline & Hypothesis & unit root & \\
\hline & Specificatio & nd intercept & \\
\hline & ak Specifica & cept only & \\
\hline & eak Type: $\mathrm{Ir}$ & 1 outlier & \\
\hline Break Selection: Mir & ze Dickey-F & istic & \\
\hline Lag Length: 0 (Aut & $\begin{array}{r}\text { - based on } \\
n\end{array}$ & nformatio & \\
\hline & & t-Statistic & Prob.* \\
\hline Augmented Dickey-l & $r$ test statist & -6.833036 & $<0.01$ \\
\hline Test critical values: & $1 \%$ level & -5.347598 & \\
\hline & $5 \%$ level & -4.859812 & \\
\hline & $10 \%$ level & -4.607324 & \\
\hline
\end{tabular}

Our test resulted in a statistic of $-6,83$, with a $\mathrm{p}$-value less than 0.01 , leading us to reject the null hypothesis of a unit root (14). To assess the trend, assuming a breakpoint exists, we apply breakpoint linear regression. This method allows the independent variable to be divided into segments and multiple models expressing the relationship between the independent variable (time) and the dependent variable (average yield) to describe the average yield behavior for different periods of time. The boundaries between the segments, called "breakpoints", are the values of the variable "time" where the slope of the linear function of the average yields changes. We perceive the value of the breakpoint as unknown, which requires it to be evaluated. When there is only one breakpoint in $\mathrm{x}=\mathrm{c}$ the pattern can be expressed by two regression equations in the following way:

$Y_{i}=\left\{\begin{array}{c}c_{1}+b_{1} \mathrm{x}_{i 1}+\varepsilon_{i 1}, \text { for } \mathrm{x}_{i 1} \leq c \\ c_{2}+b_{2} \mathrm{x}_{i 2}+\varepsilon_{i 2}, \text { for }>c\end{array}\right.$, where:

$Y_{i}$ - average yield value

$\mathrm{x}_{i 1}, \mathrm{x}_{i 2}$-values of the factor variables in the first and second regression equations

$c_{1}, c_{2}$-intercept values in the first and second regression equations $b_{1}, b_{2}$ - values of the angular coefficients in the first and second regression equations $\varepsilon_{t}$-residual component.

Breakpoints were calculated using the Bai and Perron method (15). Breakpoint regression trendline fits better with a higher coefficient of determinations $(\mathrm{R}$-squared $=0.81)$ compared to the same estimate of the linear trend. Once a breakpoint regression trendline has been fit to the data, we consider that line as representing the yield trend.

The second step involves detrending the time series data. This includes removing the fitted values $\left(\widehat{Y}_{t}\right)$ from the series of average wheat yield per decare $\left(Y_{t}\right)$, so that risk assessment can be evaluated from the residuals $\widehat{\varepsilon_{\mathrm{t}}}$. The relative detrended yield (residuals) is the departure of yield values from the time-trend, assumed to take into account the predictable technology, management and political effects on average wheat yield per decare:

$\widehat{\varepsilon_{t}}=Y_{t}-\widehat{Y}_{t} \mathrm{t}=1,2 \ldots . \mathrm{T}$

The trend in the time series has been removed by subtracting the value of the trend from the original yield data, giving a time series of 
residuals from the trend. The trend values denote the predictable yield, defined as the potential crop yield under average weather conditions $(5,6,16)$. The values of the residuals indicate the random impacts of weather and other natural events.

The final step involves calculating the value of the detrended coefficients of variation $(4,17$, 18) using formula (3):

$\mathrm{DCV}=\frac{\sigma_{\widehat{\varepsilon}}}{\bar{x}} \cdot 100$,

where:

DCV - detrended coefficients of variation

$\sigma_{\widehat{\varepsilon}^{-}}$Standard Deviation of Residuals (root mean squared error)

$\bar{x}$ - average of the original time series
The smaller the residual standard deviation is compared to the sample standard deviation, the greater the extent to which the change in average yield can be explained by foreseeable factors.

The statistical package Econometric Views (EViews) 10 Univ. was used for time series analysis.

\section{RESULTS}

Table 3 presents the results of the Bai-Perron test of sequentially determined breaks. According to this test, in the studied data from the average yield time line there is one break point in 2007.

Table 3. Bai-Perron test of $L+1$ vs. L sequentially determined breaks

\begin{tabular}{|c|c|c|c|}
\hline \multicolumn{3}{|c|}{ Sequential F-statistic determined breaks: } & \multirow[b]{2}{*}{ Critical } \\
\hline & & Scaled & \\
\hline Break Test & F-statistic & F-statistic & Value** \\
\hline 0 vs. $1 *$ & 5.839725 & 11.67945 & 11.47 \\
\hline 1 vs. 2 & 4.008549 & 8.017097 & 12.95 \\
\hline \multicolumn{4}{|c|}{ * Significant at the 0.05 level. } \\
\hline \multicolumn{4}{|c|}{ ** Bai-Perron (Econometric Journal, 2003) critical values. } \\
\hline \multicolumn{2}{|c|}{ Break dates: } & & \\
\hline & Sequential & Repartition & \\
\hline & & & \\
\hline
\end{tabular}

The results of the breakpoint regression analysis performed are presented in Table 4.

Table 4. Breakpoint linear regression analysis results

\begin{tabular}{|c|c|c|c|c|}
\hline \multicolumn{5}{|c|}{ Method: Least Squares with Breaks } \\
\hline Variable & Coefficient & Std. Error & $\mathrm{t}$-Statistic & Prob. \\
\hline \multicolumn{5}{|c|}{$1998-2006--9$ obs } \\
\hline $\mathrm{C}$ & 268.6476 & 6.656602 & 40.35806 & 0.0000 \\
\hline @TREND (b1) & 8.270333 & 1.818483 & 4.547931 & 0.0003 \\
\hline \multicolumn{5}{|c|}{$2007-2018--12$ obs } \\
\hline $\mathrm{C}$ & 108.7116 & 51.38446 & 2.115651 & 0.0494 \\
\hline @TREND (b2) & 20.63696 & 3.136284 & 6.580067 & 0.0000 \\
\hline R-squared & 0.813555 & \multicolumn{2}{|c|}{ Mean dependent var } & 362.4252 \\
\hline Adjusted R-squared & 0.780653 & \multicolumn{2}{|c|}{ S.D. dependent var } & 86.95516 \\
\hline S.E. of regression & 40.72500 & \multicolumn{2}{|c|}{ Akaike info criterion } & 10.42120 \\
\hline Sum squared resid & 28194.94 & \multicolumn{2}{|c|}{ Schwarz criterion } & 10.62016 \\
\hline Log likelihood & -105.4227 & \multicolumn{2}{|c|}{ Hannan-Quinn criter. } & 10.46438 \\
\hline F-statistic & 24.72659 & \multicolumn{2}{|c|}{ Durbin-Watson stat } & 3.116099 \\
\hline Prob(F-statistic) & 0.000002 & & & \\
\hline
\end{tabular}

Based on the breakpoint linear regression analysis, we come to the following conclusions: First, the coefficients of determination (R-squared and Adjusted Rsquared) are equal to 0.81 and 0.78 i.e. the model describes $78 \%$ to $81 \%$ of the average yield variations over time. Second, this breakpoint linear regression model is adequate (the probability value of the F-criterion is less than the accepted significance level $\alpha=0.05$ $($ Prob $($ F-statistic $)=0.000002<\alpha)$. Third, the values of the constants (c) as well as the values 
of the angular coefficients (b) in the regression equations are statistically significant and consequently can be interpreted. The average yield is on average increased under the influence of foreseeable factors by $8 \mathrm{~kg} /$ decare in the period 1998-2006 and by $21 \mathrm{~kg} /$ decare in the period 2007 - 2018. The change in the rate of growth of the average yield (Figure № 1) can be explained by a structural shock in the values of long-term impact factors after 2007, such as technological innovations, know-how, etc.

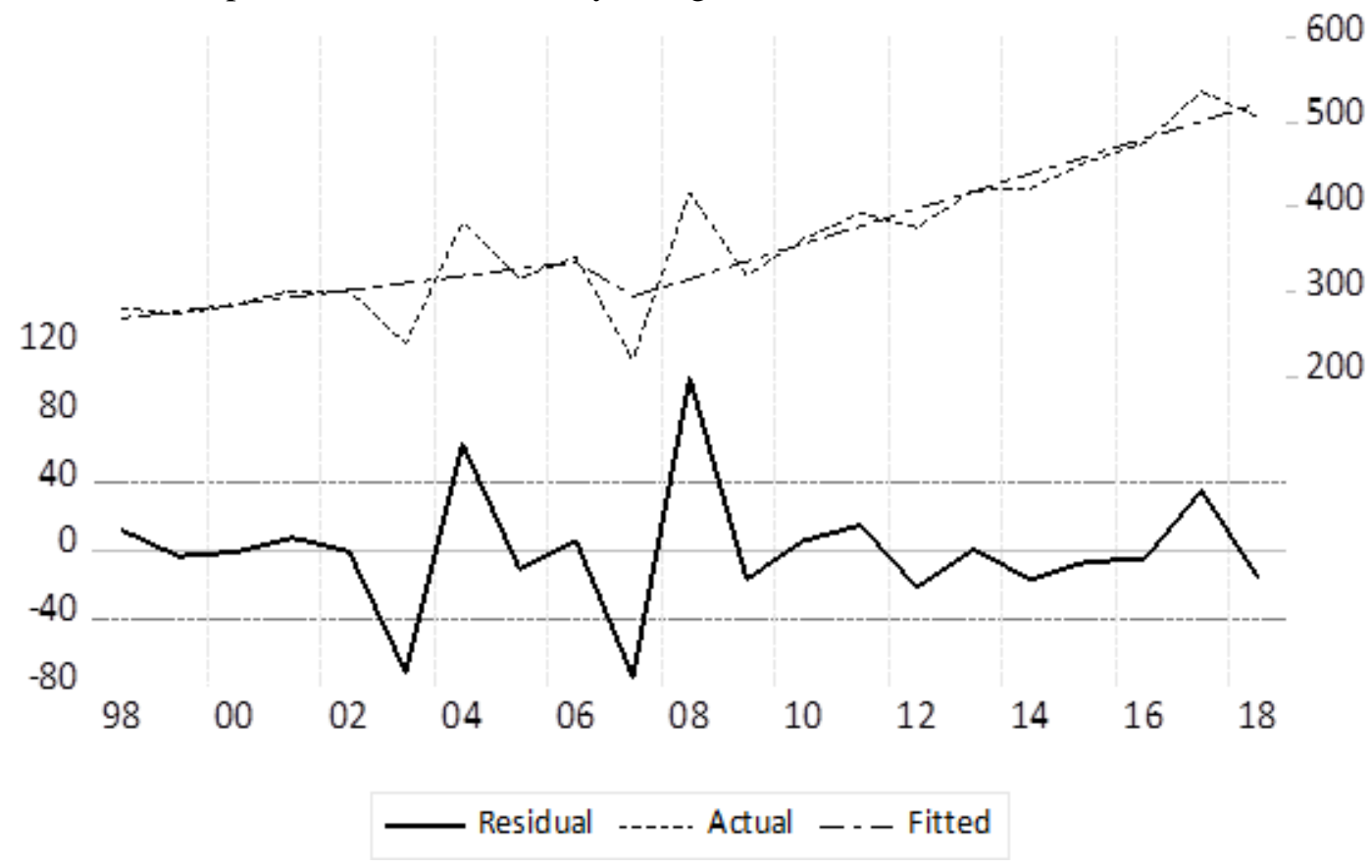

Figure 1. Components of the time series of the average yield when considering the existence of a breakpoint in 2007

Source: author's calculations, based on FAOSTAT data

To estimate the risk of climate variability, we calculate the coefficient of variation of the residuals (Table 5).

Table № 5. Average yield coefficient of variation $(C V)$ and detrended coefficient of variation (DCV)

\begin{tabular}{|c|c|c|c|c|c|}
\hline Variable & $N$ & Mean & Std. Deviation & $C V(\%)$ & $D C V(\%)$ \\
\hline $\begin{array}{l}\text { Average wheat } \\
\text { yield }\end{array}$ & 21 & 362,4252381 & 86,95516089 & 23,99 & - \\
\hline Residuals & 21 &, 0000000 & 37,54659824 & & 10,35 \\
\hline
\end{tabular}

The average yield variation around its average (typical) value for the period is about $24 \%$. Approximately $10 \%$ of the average yield variations from its typical value can be explained by unpredictable factors.

\section{CONCLUSIONS}

On the basis of this study, we draw the following conclusions: Firstly, the estimation of the predictable component in the time series of the average wheat yield in Bulgaria should take into account the presence of a structural shock in the trend, which can be explained mainly by the influence of political factors after 2007. Secondly, about $10 \%$ of the average yield variation from its typical value over the period 1998-2018 can be explained by the impact of random factors.

The proposed methodology could be useful for making climate risk comparisons for different agricultural products as well as for comparing the level of risk resulting from climate variability to the level of price risk associated with selected crops.

\section{REFERENCES}

1. European Commission, Directorate General JRC Joint Research Centre. Agricultural 
Insurance Schemes Summary report, November 2006

2. National Association of Grain Producers. National strategy for the development of the grain sector, May, 2013

3. Bharat R., S. Ravi, S.D. Chopra, Risk management in agriculture. Discussion Paper 03-08, Indian Statistical Institute, Delhi Planning Unit , 2003.

4. Gommes R., L.O. Fresco, Everybody complains about climate...What can agricultural science and the CGIAR do about it? Mobilizing Science for Global Food Security. CGIAR Mid-Term Meeting 1998, May 25-29, Brasília, Brazil,1998.

5. Ye, T., J. Nie, J. Wang, P. Shi, Z. Wang, Performance of detrending models of crop yield risk assessment: evaluation on real and hypothetical yield data. Stochastic Environmental Research and Risk Assessment 29(1):109-117, 2015.

6. A. H. Choudhury, J. R. Jones, R. Choudhury, and A. D. Spaulding, Association of Rainfall and Detrended Crop Yield Based on Piecewise Regression for Agricultural Insurance. Journal of Economics and Economic Education Research, 16(2): 31-43, 2015.

7. http://www.fao.org/faostat/en/\#data

8. Ivanova K., Assessment of the direct payments impact on Bulgarian wheat. Bulgarian Journal of Agricultural Economics and Management, 59 (3): 73-78, 2014.

9. Linkova, M., The Common Agricultural Policy and the Localization of Investments in Agriculture. Management and Sustainable Development. 6: 13-18, 2012.
10. Bachev H., Assessment of Impacts of EU CAP Implementation on Bulgarian Farms. Bulgarian Journal of Agricultural Economics and Management, 57 (1): 14-29, 2012.

11. EUROPEAN COMMISSION Directorate-General for Agriculture and Rural Development - Unit C.4 (2017): Guidelines. Evaluation of innovation in rural development programmes 2014-2020.

12. Noriega, A. E., Ventosa-Santaulària, D. Spurious Regression and Trending Variables. Oxford Bulletin of Economics and Statistics , 69( 3): 439-444, 2007.

13. Maradiaga, David I., Stochastic trends in crop yield density estimation. LSU Master's Theses. 3004, LSU, 2010.

14. Eviews User's Guide (http://www.eviews.com/help/helpintro.htm l\#page/content/advtimeser-

Unit_Root_Tests_with_a_Breakpoint.html

15. Eviews User's Guide http://www.eviews.com/help/helpintro.html \#page/content\%2Fmultibreak-

Least_Squares_with_Breakpoints.html\%23

16. O. Läänemets, A.-H. Viira, M. Nurmet, Price, Yield, and Revenue Risk in Wheat Production in Estonia. Agronomy Research, 9:421-426, 2011.

17. Moledina, A., R., Terry, S., Mathew , Measuring Commodity Price Volatility And The Welfare Consequences Of Eliminating Volatility, 2004 Annual meeting, August 14, Denver, CO 19963, American Agricultural Economics Association (New Name 2008: Agricultural and Applied Economics Association), 2004.

18. R. Chand, S S Raju, S. Garg, L. Pandy, Instability and Regional Variation in Indian Agriculture. NCAP, New Delhi, 2011 